\title{
Management of Severely Displaced Fronto-Zygomatico- Orbital Fracture in a Child
}

${ }^{1}$ Satnam Singh, ${ }^{2} \mathrm{~S}$ Shanthanam, ${ }^{3}$ Akshat Gupta, ${ }^{4}$ Sachin Rai

\begin{abstract}
The paper presents a rare case of severely fractured and displaced fronto-zygomatico-orbital fracture in a 4-year-old child. The case was managed with open reduction and internal fixation. The paper highlights the importance of early and multidisciplinary approach to such craniofacial injuries.
\end{abstract}

Keywords: Zygomatico-orbital fracture, Frontal bone fracture, Open reduction, Internal fixation, Post-traumatic blindness, Pediatric maxillofacial injuries.

How to cite this article: Singh S, Shanthanam S, Gupta A Rai S. Management of Severely Displaced Fronto-ZygomaticoOrbital Fracture in a Child. J Postgrad Med Edu Res 2014; 48(2):103-104.

\section{Source of support: Nil}

Conflict of interest: None

\section{INTRODUCTION}

Maxillofacial injuries in children less than 5 years of age are rare due to retro-positioned face and the larger diameter of the head. The thick layer of adipose tissue covers the elastic bones and the suture lines are flexible. ${ }^{1}$ Fractures of the lateral wall of orbit are seen in zygomaticomaxillary complex injuries due to severe facial trauma. ${ }^{2}$ These kind of fractures usually occurs in young male patients but rarely in children. ${ }^{3}$ Fracture of the orbit may be associated with blindness and intracranial injuries. ${ }^{4}$ Radiographic assessment is very important for management of significantly displaced fracture and associated ophthalmic and intracranial injuries. ${ }^{5}$ We are reporting a rare case of comminuted fracture of right zygoma, orbit and frontal bone in a 4-yearold child. The patient was managed with open reduction and internal fixation in association with neurosurgeon

\footnotetext{
${ }^{1}$ Former Senior Resident, ${ }^{2}$ Senior Resident

${ }^{3}$ Junior Resident, ${ }^{4}$ Assistant Professor

1,3,4 Unit of Oral and Maxillofacial Surgery, Oral Health Sciences Centre, Postgraduate Institute of Medical Education and Research, Chandigarh, India

${ }^{2}$ Department of Neurosurgery, Postgraduate Institute of Medical Education and Research, Chandigarh, India

Corresponding Author: Sachin Rai, Assistant Professor Unit of Oral and Maxillofacial Surgery, Oral Health Sciences Centre, Postgraduate Institute of Medical Education and Research, Chandigarh, India, Phone: 2756261, e-mail: drraisachin@gmail.com
}

highlighting the importance of multidisciplinary approach to craniofacial trauma.

\section{CASE REPORT}

A 4-year-old male child suffered injury on the right side of the face in a road accident and was brought to the trauma emergency. There was a large laceration on the face extending from the central forehead to the medial aspect of right eye through which brain matter was herniating (Fig. 1). He was conscious and his computerized tomographic (CT) scan of head and face was done. Immediate neurosurgery and ophthalmology consultation was taken. Comminuted fractures of frontal, temporal bone and severely displaced zygoma and orbit with cerebrospinal fluid (CSF) leak were diagnosed (Fig. 2). There was no penetrating injury to the globe but globe was displaced laterally and there was complete loss of vision. Under general anesthesia, repair of dural rent was done with fascia lata by the neurosurgeon. This was followed by the reconstruction of the frontal bone, zygoma and the orbit with miniplates and orbital mesh by the maxillofacial team. Postoperative recovery was uneventful and the CT scan revealed an anatomically reduced bony fracture (Fig. 3). The child lost the vision in his right eye

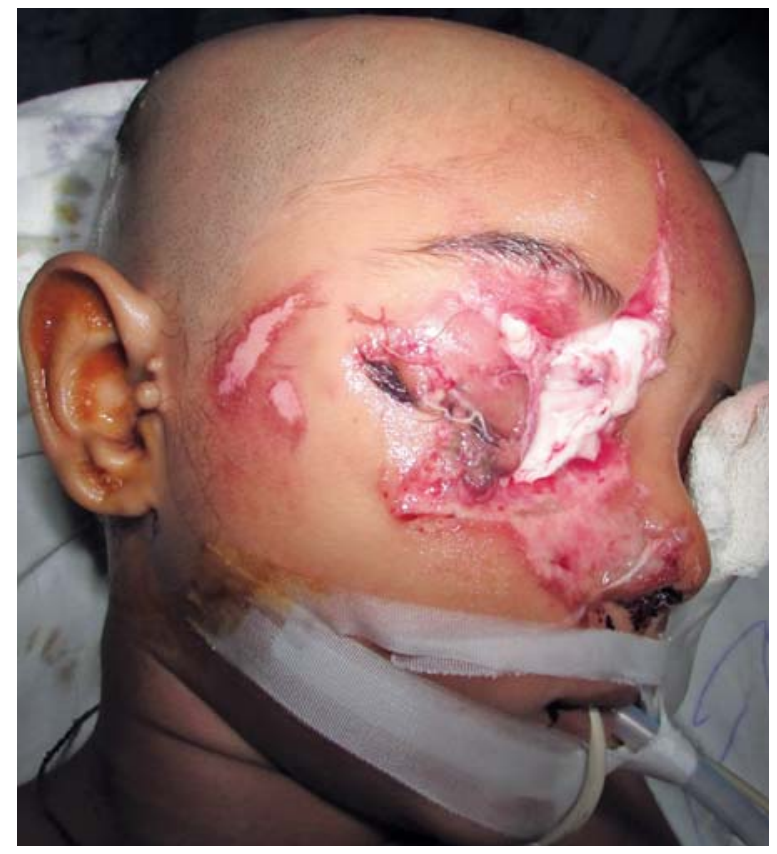

Fig. 1: Laceration in medial side of right eye through which brain matter is visible. The eyeball is displaced laterally with complete loss of vision 


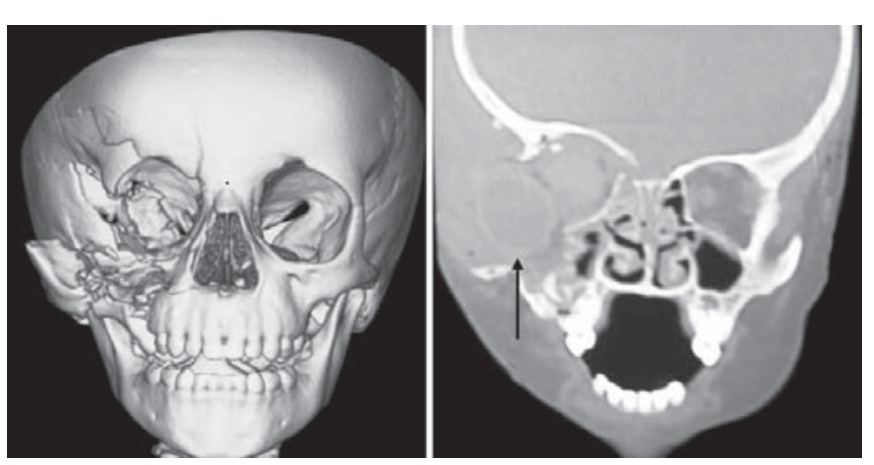

Fig. 2: CT scan shows severely displaced and comminuted fracture of right frontal bone, zygoma and orbit and a laterally displaced globe (arrow)
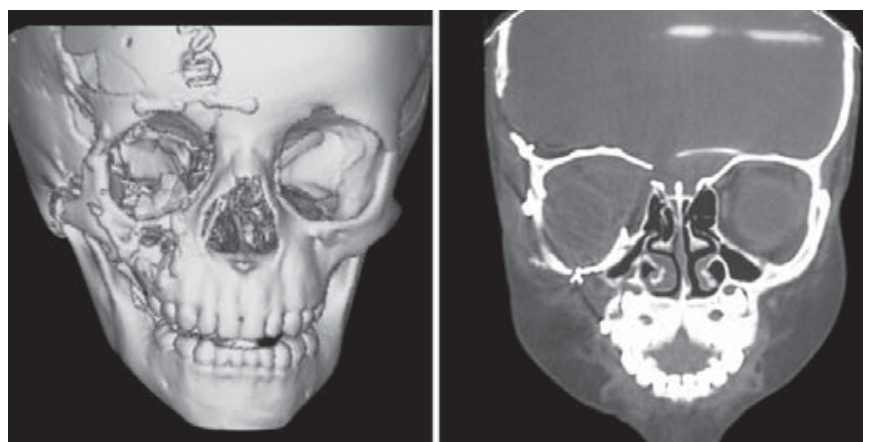

Fig. 3: CT scan depicting reduction and fixation of all the fracture sites with miniplates

permanently. There was soft tissue contraction with ptosis of right eyelid and inadequate positioning of medial canthal ligament (Fig. 4).

\section{DISCUSSION}

Pediatric maxillofacial injuries are managed conservatively owing to their minimal displacement. High velocity trauma results in severe comminution and displacement of the facial bones wherein other vital structures are permanently damaged. Early and definitive management of both hard and soft tissue are very important in children to minimize post-traumatic orbital and zygomatic complex deformities.

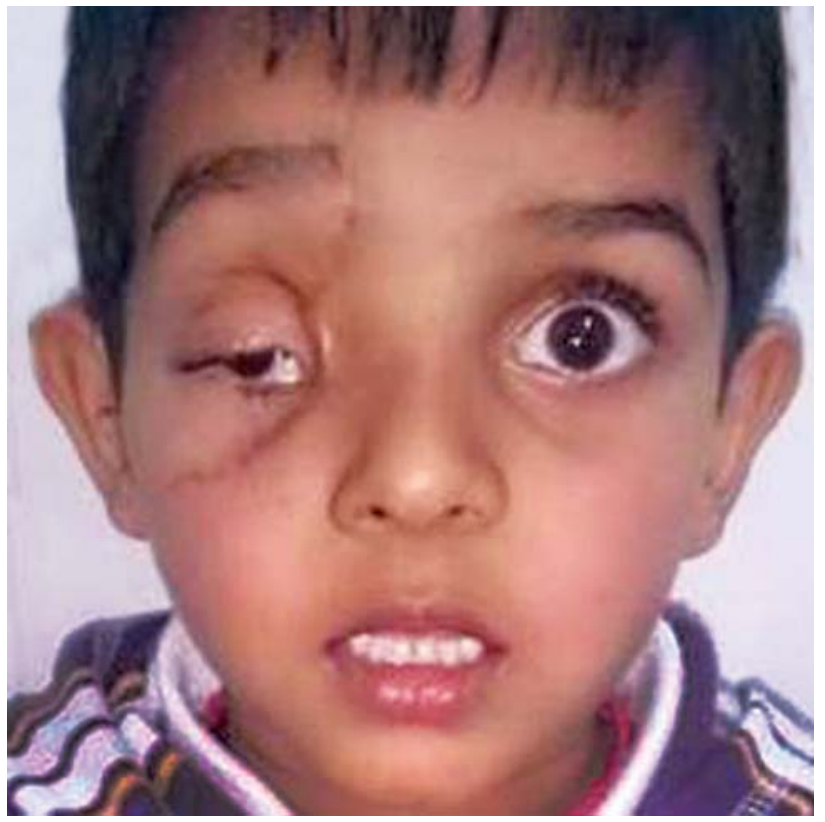

Fig. 4: Postoperative picture showing residual scar and ptosis of right eye

A multidisciplinary approach to complex craniofacial trauma is the key to a successful outcome.

\section{REFERENCES}

1. Zimmermann CE, Troulis MJ, Kaban LB. Pediatric facial fractures: recent advances in prevention, diagnosis and management. Int J Oral Maxillo Fac Surg 2006;35:2-13.

2. Cerulli G, Carboni A, Mercurio A, et al. Soccer related craniomaxillofacial injuries. J Cran Fac Surg 2002;13:627-630.

3. Ferrira P, Marques M, Pinto C, et al. Midfacial fractures in children and adolescent: a review of 92 cases. British J Oral Max Fac Surg 2004;42:501-505.

4. Becelli R, Renzi A, Perugini M, et al. Craniofacial trauma immediate and delayed treatment. J Cran Fac Surg 2000;11: 265-269.

5. Tsau H, Jeng SF, Lint S, et al. Predictive value of computerized tomographic in visual outcome in indirect treatment optic neuropathy complicated with periorbital facial bone fractures. Clin Neurol Neurosurg 2005;107:200-206. 